\title{
Expectativas dos agentes e efeitos das políticas monetárias e fiscais críveis nos índices setoriais da bolsa de valores brasileira ${ }^{1}$
}

\author{
Daniel Augusto de Souza* \\ Adriano de Amarante** \\ Fernando Pozzobon*** \\ Patrícia Silva Felini****
}

\section{Resumo}

Um ambiente de estabilidade macroeconômica é crucial para a determinação de um nível ótimo de consumo e investimento e, também, para alocações de recursos econômicos e financeiros por parte dos agentes econômicos como consequência de uma boa previsão quanto às condições futuras da economia. Este artigo buscou analisar para o Brasil em que medida as políticas econômicas críveis afetam os seguintes índices setoriais do Ibovespa: Índice Industrial (INDX), Índices de Empresas de Energia (IEE), Índice do Consumo (ICON) e Índice Financeiro (IFNC). Neste estudo testa-se a hipótese de que a credibilidade da política fiscal e da política monetária afetam os índices setoriais da Brasil, Bolsa, Balcão (B3) e seus retornos. Por meio de uma análise de cointegração e com o método do Mecanismo de Correção de Erros (MCE), os resultados mostraram que a credibilidade da política monetária e a credibilidade da política fiscal não são cointegrados aos índices para o período compreendido entre 2002 a 2016. Por outro lado, as variações do Ibovespa afetaram o IFNC e as regressões entre os retornos e os índices de credibilidade apontaram significância estatística dos efeitos da credibilidade de política monetária sobre as taxas de retorno dos índices.

Palavras-chave: Credibilidade. Política monetária. Política fiscal. Índices setoriais.

\section{Expectations of agents and the effects of monetary and fiscal policies credit on the brazilian securities exchange sector index}

\begin{abstract}
An environment of macroeconomic stability is crucial for determining an optimal level of consumption and investment and, also, for allocations of economic and financial resources by economic agents as a consequence of a good prediction of future economic conditions. This study sought to analyze for the extent to which credible economic policies affect the Ibovespa indexes: Industrials Index (INDX), Electric Utilities Index (IEE), Consumer Stock Index (ICON) and Financials Index (IFNC). This article tests the hypothesis that the credibility of fiscal policy and monetary policy affect the sectoral indices of the B3 and their returns. Through a cointegration analysis and the Error Correction Mechanism (ECM) method, the results showed that the credibility of the monetary policy and the credibility of the fiscal policy are not cointegrated with the analyzed indices for the period between 2002 and 2016. On the other hand, Ibovespa variations affected the IFNC and the regressions between returns and credibility indices pointed statistical significance of the effects of monetary policy credibility on rates of return of indices.

\footnotetext{
* Professor da Universidade do Estado de Santa Catarina (UDESC/ESAG). E-mail: desouza.esag@gmail.com ** Professor da Universidade do Estado de Santa Catarina (UDESC/ESAG). E-mail: adriano.amarante@udesc.br ***Professor da Universidade do Estado de Santa Catarina (UDESC/ESAG). E-mail: fernando.esag@gmail.com ****Mestranda em Economia na Universidade de São Paulo (USP) Campus de Ribeirão Preto - SP. E-mail: patricia.felini@usp.br
}

\footnotetext{
${ }^{1}$ Agradecemos a FAPESC pelo o apoio ao desenvolvimento da pesquisa que resultou no artigo.
} 
Keywords: credibility, monetary policy, fiscal policy, sectoral index

JEL: E52, E62

\section{Introdução}

A partir da publicação do trabalho de Kydland e Prescott (1977), no qual se mostrou que um banco central discricionário gera um viés inflacionário na economia, diversos estudos foram elaborados com o objetivo de mensurar o efeito da credibilidade da política monetária no desempenho da economia.

Diante do debate entre regras e discricionariedade, a partir da década de 1990 vários países começaram a adotar o regime de metas para inflação com o objetivo de manter a inflação compatível com a meta estabelecida e estável. O primeiro país a adotar o regime de metas para inflação foi a Nova Zelândia (1990), seguido do Canadá (1991), Chile (1991), Reino Unido (1992), Austrália (1993), entre outros. No Brasil, esse regime foi adotado em 1999 e a partir desse momento a credibilidade do Banco Central passa a ter um papel relevante para que o regime de metas de inflação seja bem-sucedido e, consequentemente, gere um ambiente macroeconômico estável.

Um ambiente de estabilidade macroeconômica é de fundamental importância para a determinação dos agentes econômicos quanto ao nível ótimo de consumo e investimento e para a realização de previsões quanto às condições futuras da economia.

Contudo, para que a inflação convirja para a meta e as expectativas dos agentes reflitam que isso irá ocorrer, a condução da política fiscal também precisa ter credibilidade. Nestes termos, é necessário que as políticas monetárias e as políticas fiscais sejam críveis para que o sistema de metas para inflação atinja seu objetivo.

A lei complementar $n^{\circ} 101$, de 4 de maio de 2000, estabeleceu o marco regulatório das finanças públicas, porque a lei visa estabelecer responsabilidade fiscal nas contas públicas dos três entes do governo brasileiro. Dessa forma, o estabelecimento dessa lei sinaliza para a sociedade o comprometimento com metas fiscais, as quais contribuem para dar transparência e sustentabilidade para as finanças públicas. Além de contribuírem para evitar pressões inflacionárias na economia.

Neste sentido, se as finanças públicas não estiverem equilibradas (por exemplo: crescimento contínuo da relação dívida/PIB) a utilização da política monetária para debelar a 
inflação pode gerar elevadas taxas de juros e implicar em uma relação insustentável das despesas públicas. Por isso, as políticas monetárias e fiscais devem atuar de maneiras coordenadas.

É recorrente encontrar na literatura econômica, evidências de que uma política monetária crível promoverá um ambiente macroeconômico estável e, consequentemente, elevará o investimento porque reduzirá os riscos associados à incerteza com relação ao futuro. Contudo, não é recorrente na literatura estudos que analisem para o Brasil os efeitos das credibilidades tanto das políticas monetárias e das políticas fiscais.

Partindo do cenário apresentado, o presente trabalho busca responder a seguinte questão: em que medida para o Brasil a credibilidade das políticas monetárias e fiscais afetam as decisões de investimento dos agentes atuantes na bolsa de valores brasileira (B3)?

Para responder a essa pergunta, o objetivo geral deste trabalho é analisar empiricamente para o Brasil qual a influência das políticas monetárias e fiscais críveis nas decisões dos investidores que atuam na B3.

Adicionalmente ao objetivo geral, buscar-se atender os seguintes objetivos específicos :i) apresentar o referencial teórico; ii) apresentar estudos anteriores relacionados ao assunto; iii) aplicar a metodologia econométrica; e, iv) demonstrar os resultados obtidos e os tratamentos estatísticos utilizados.

Mensurar para o Brasil se a credibilidade da política monetária afeta as decisões dos investidores na bolsa de valores. Para tanto, analisa-se o impacto da condução da política monetária brasileira nas variáveis: número de negócios na bolsa de valores brasileira, volume de negócios na bolsa de valores brasileira e o comportamento do Ibovespa (fechamento).

\section{Revisão bibliográfica}

Nesta seção, faz-se um apanhado sobre as teorias e estudos feitos sobre o impacto da credibilidade das políticas monetárias e fiscais na economia brasileira. Estes estudos passaram a assumir relevância com o desenvolvimento do debate entre discricionariedade versus regras, em relação as ações do policymaker.

A partir do trabalho de Kyndland e Prescott (1977), no qual os autores demonstram que a política discricionária não consegue maximizar a função bem estar social, mesmo quando o ciclo econômico é conhecido; e, a partir do trabalho de Barro e Gordon (1983) no 
Revista Catarinense de Economia -RCE

APEC - Associação dos Pesquisadores em Economia Catarinense

10 Semestre de 2018 - www.apec.pro.br/rce

qual os autores mostram que o comprometimento contínuo do Banco Central com as regras de política monetária, desempenha um papel importante para que a inflação se mantenha baixa e estável. Em verdade, são estudos e teorias que visam analisar a influência da credibilidade da política econômica no funcionamento da economia.

Nestes estudos são apresentados mecanismos de política econômica visando o compromisso das ações do policymaker. Por exemplo, o regime de metas para inflação requer o comprometimento da autoridade monetária com o seu principal objetivo, o qual é manter a inflação estável e na meta.

Mankiw (2011) destaca que a política econômica é guiada por regras, se os formuladores de políticas públicas anunciarem antecipadamente a forma como a política reagirá a diversas situações, além de se comprometerem a seguir o que foi anunciado. A política econômica será conduzida pelo poder discricionário, se os formuladores de políticas públicas estiverem livres para escolherem suas ações à medida que as flutuações econômicas acontecerem.

A falta de confiança no conhecimento técnico econômico dos políticos faz com que muitos economistas e cientistas políticos defendam que a política econômica possua regras, para serem seguidas. Além da manipulação da economia por parte dos políticos para fins eleitoreiros, a chamada teoria do ciclo econômico político, constitui outro argumento em favor das regras na condução da política econômica.

Segundo essa teoria, desenvolvida por Nordhaus (1975), se os eleitores votam com base nas condições econômicas do momento das eleições, os políticos têm o incentivo para adotar políticas econômicas que façam com que a economia pareça estar bem durante o período da eleição. Passado esse período, nada impede que os políticos eleitos adotem medidas para frear a economia com o objetivo de controlar a inflação, e à medida que a próxima eleição vá se aproximando, esses políticos voltem a tomar medidas expansionistas para estimular a economia.

O problema da inconsistência temporal das políticas econômicas é outro argumento em favor das regras, em detrimento da discricionariedade. Esse problema reside no fato que depois do governo ter anunciado antecipadamente a política econômica que irá adotar e, assim influenciar as expectativas dos agentes econômicos, o governo pode se sentir tentado a voltar atrás e não cumprir seu pronunciamento.

Por exemplo, um governo com o objetivo de estimular o investimento no país anuncia que não irá tributar o rendimento oriundo do capital. Contudo, após as fábricas terem sido 
Revista Catarinense de Economia -RCE

APEC - Associação dos Pesquisadores em Economia Catarinense

10 Semestre de 2018 - www.apec.pro.br/rce

construídas, o governo se sente tentando a descumprir sua promessa com o objetivo de aumentar sua arrecadação a partir dos rendimentos do capital.

Um argumento em favor do poder discricionário, considerando o pressuposto que a população confia nos formuladores de políticas públicas, é a flexibilidade do poder discricionário. Se os policymakers são bem preparados para as suas funções, há poucas razões para que eles não possuam o poder decisório da política econômica para responder as flutuações e aos choques econômicos.

Contudo, os agentes racionais compreendem os incentivos que podem fazer com que os formuladores de políticas públicas voltem atrás dos seus pronunciamentos e, dessa forma, essa expectativa influencia o comportamento desses agentes. Por isso, segundo Mankiw (2011), a solução é tirar o poder discricionário dos policymakers por meio de um compromisso digno de credibilidade para com uma regra de política econômica fixa.

Já Blanchard (2013) sugere outra solução para o problema de inconsistência temporal das políticas econômicas. Ele argumenta que uma regra fixa (por exemplo, uma taxa de crescimento constante da moeda para a política monetária ou a obrigatoriedade de um orçamento equilibrado para a política fiscal), gera grandes custos porque impede o uso da política econômica.

Dessa forma, ele aponta três medidas para resolver o problema, as quais são: independência do Banco Central, visão de longo prazo da autoridade monetária e o banqueiro central ser conservador. As duas primeiras medidas servem para construir credibilidade e a terceira medida assegura que o banqueiro central seja alguém que se preocupa mais com a inflação e menos com a taxa de desemprego do que o governo.

Para Mishkin (2007), para manter a inflação na meta e estável é necessário não apenas uma política monetária comprometida com suas metas, mas também uma política fiscal. Nesse sentido, as políticas monetárias e fiscais devem atuar de maneiras coordenas, pois, a utilização da política monetária para controlar a inflação, sem que as finanças públicas estejam equilibradas, pode resultar em elevadas taxas de juros.

Dornbusch, Fischer e Startz (2013) apontam para o dilema de curto prazo entre inflação e desemprego dado pela curva de Phillips de curto prazo. Contudo, devido ao ajuste de expectativas de inflação, não há dilema no longo prazo. A melhor posição para a economia no longo prazo é o pleno emprego com inflação zero. No entanto, o policymaker que anuncia uma política de pleno emprego e inflação zero, terá incentivos para enganar o público ao buscar um desemprego um pouco menor e uma inflação um pouco maior. Esta divisão entre 
planos anunciados e planos executados dá origem ao problema chamado de inconsistência dinâmica.

O Gráfico 1 a seguir mostra o dilema da curva de Phillips entre desemprego e inflação. O ponto A é o preferido tanto dos formuladores de políticas econômicas quanto da população. Nesse ponto, o policymaker promete e a população espera inflação zero. Se a economia atingir o ponto A, o formulador de políticas econômicas estará disposto a aumentar a inflação um pouco para reduzir o desemprego. Então, a economia se deslocará para o ponto B onde a inflação é alta o suficiente apenas para que o benefício marginal de menor desemprego se iguale a perda marginal de maior inflação.

Gráfico 1 - A curva de Phillips e a Política Econômica

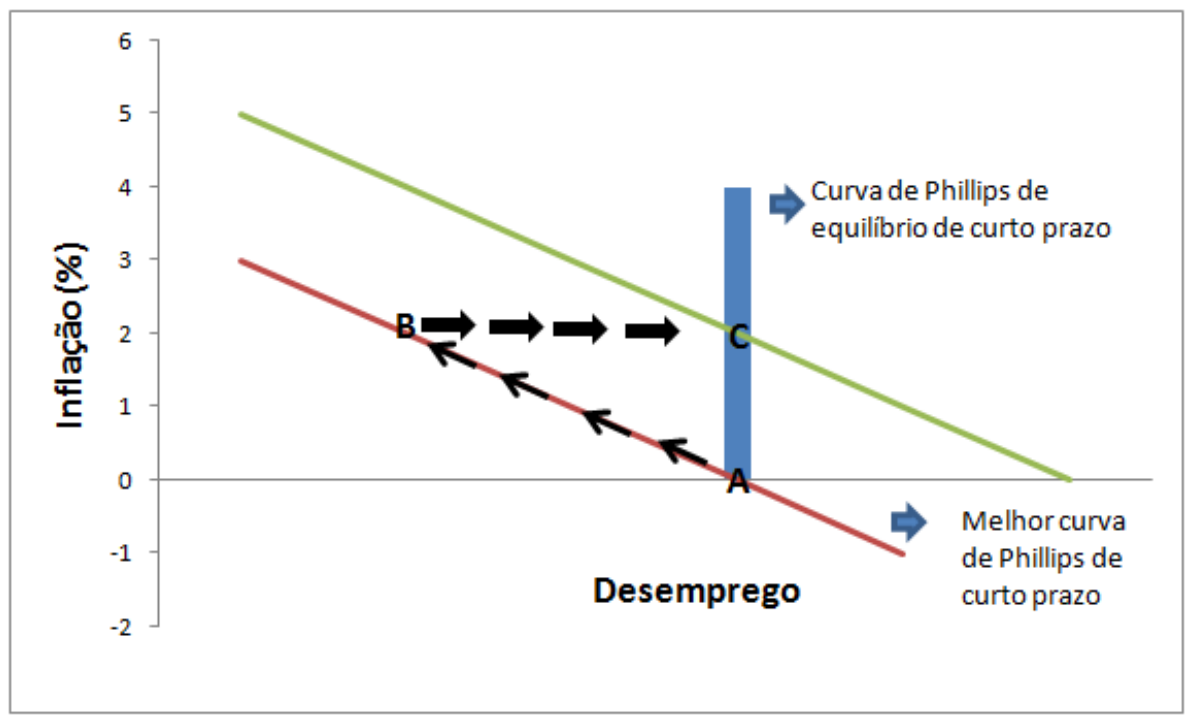

Fonte: Elaboração dos autores, a partir de Dornbusch, Fischer e Startz (2013, p. 431)

No ponto $\mathrm{B}$, a inflação é mais alta que o antecipado e os agentes econômicos, consequentemente, anteciparão uma inflação mais elevada. Então, a economia atinge o equilíbrio no ponto $\mathrm{C}$, o qual é um ponto de pleno emprego, mas com inflação positiva. Nesse ponto, a perda marginal da inflação é alta o suficiente para que não haja incentivos para reduzir ainda mais o desemprego.

Em equilíbrio a economia não permanece no ponto $\mathrm{A}$, mesmo esse sendo o ponto preferido de todos, mas a economia acaba com inflação alta no ponto C. Nesse ponto, o formulador de políticas econômicas irá anunciar a voltar da inflação zero e permanecer no ponto A. Entretanto, o anúncio não tem credibilidade porque se a economia voltasse para o 
Revista Catarinense de Economia -RCE

APEC - Associação dos Pesquisadores em Economia Catarinense

10 Semestre de 2018 - www.apec.pro.br/rce

ponto A, iriam existir novamente incentivos para descolar em direção ao ponto B e reiniciar o ciclo.

Os autores apontam para formas de resolver o problema de inconsistência dinâmica, as quais são: a autoridade monetária manter uma reputação de consistência, o banqueiro central possuir um perfil mais anti-inflacionário do que o público em geral, o estabelecimento de um contrato entre o Banco Central e o governo no qual existam pagamentos que recompensem a inflação baixa e, por fim, o estabelecimento de regras de inflação.

Salto e Almeida (2016) descrevem quais seriam os canais de influência recíproca entre as políticas fiscal e monetária. Primeiramente, o principal canal de influência da política fiscal sobre a atuação do Bacen se materializa quando elevados déficits públicos acabam sendo financiados pela emissão de moeda. Nessa situação, uma política fiscal expansionista leva a uma política monetária também expansionista. No Brasil, há vedação legal ao financiamento do Tesouro pelo Bacen².

Contudo, mesmo quando o Tesouro financia seus gastos com emissão de dívida pública no mercado brasileiro, a política monetária é afetada devido ao efeito conhecido como crowding-out ${ }^{3}$. A tomada de recursos no mercado por parte do Tesouro reduz o espaço do crédito privado, o que tem efeitos relevantes para o crescimento da economia e, consequentemente, induz o Bacen a recalibrar de forma compensatória a política monetária (SALTO E ALMEIDA, 2016).

A inércia inflacionária é outro canal de influência da política fiscal sobre a atuação do Banco Central. Por exemplo, se o Governo financia seus déficits com expressivos aumentos de impostos indiretos, a elevação de preços resultante pode demandar medidas do Bacen para limitar os efeitos inflacionários. Um terceiro canal de influência da orientação fiscal sobre a política monetária em países nos quais o Tesouro é o controlador de instituições bancárias, caso do Brasil, é a expansão do crédito pelos bancos públicos.

Segundo Salto e Almeida (2016) há também diversos canais que a política monetária pode afetar a política fiscal, entretanto o mais visível e relevante é por meio da fixação da taxa básica de juros, porque ela afeta o custo de endividamento do Tesouro. Dessa forma, quando a sustentabilidade do endividamento público é posta em risco, as expectativas negativas dos

\footnotetext{
${ }^{2}$ Constituição Federal, artigo 164, parágrafo $1^{\circ}$ : "É vedado ao Banco Central conceder, direta ou indiretamente, empréstimo ao Tesouro Nacional e a qualquer órgão ou entidade que não seja instituição financeira".

${ }^{3} \mathrm{O}$ 'efeito deslocamento' ou efeito crowding out é o termo denominado a explicação teórica para de ausência de efeitos sobre a demanda agregada de uma política aumento nos gastos públicos que são compensados pela queda do investimento privado provocado pelo aumento da taxa de juros resultante da expansão fiscal.
} 
agentes econômicos sobre o futuro da economia podem provocar uma crise de confiança e, consequentemente, pode paralisar o mercado de títulos públicos e gerar uma crise financeira.

As influências recíprocas entre as políticas fiscal e monetária criam uma situação de interdependência entre ambas. Desse modo, há duas situações diferentes de relação entre ambas as políticas. Na primeira situação, o Banco Central determina de forma independente a quantidade de moeda a ser emitida, de acordo com sua meta de controle de inflação. $\mathrm{Na}$ segunda situação, a autoridade fiscal determina de que forma irá financiar seus déficits colocação de títulos ou emissão de moeda (senhoriagem). Essa situação é chamada de dominância fiscal e a sua ausência é pré-requisito chave para o funcionamento do regime de metas para inflação (SALTO E ALMEIDA, 2016).

\subsection{Revisão teórica}

Alguns estudos, os quais são revisados nesta seção, mostram que o sucesso do regime de metas para inflação está correlacionado com a credibilidade do mesmo. Este regime de política econômica representa um mecanismo de compromisso da autoridade monetária em promover uma desinflação gradual nos preços e manter os ganhos obtidos com a estabilização da inflação.

Dentre os estudos empíricos relacionados ao assunto, destaca-se o trabalho elaborado por De Mendonça (2004), em que apresenta um índice que mensura a credibilidade da autoridade monetária. O índice elaborado pelo autor varia entre 0 e 1 . Quando a inflação anual esperada é igual à meta anual de inflação, o índice possui valor igual a 1.

O índice assume valor igual a 0 quando a expectativa inflacionária está acima do limite superior (teto da meta) ou abaixo do limite inferior (piso da meta) estabelecido pela autoridade monetária para o período. Se a expectativa inflacionária estiver dentro do limite máximo e do limite mínimo, o índice assume valor entre 0 e 1 . Dessa forma, à medida que a expectativa de inflação se desvia da meta o índice diminui de forma linear, como pode ser observado na Equação 1 apresentada a seguir:

$$
\operatorname{CRED}_{\mathrm{M}}=\left\{\begin{array}{c}
1 \text { se } \mathrm{E}(\pi)=\pi_{\mathrm{t}}^{\mathrm{m}} \\
1-\frac{1}{\pi_{\mathrm{tMax}}^{*}-\pi_{\mathrm{tMin}}^{*}}\left[\mathrm{E}(\pi)-\pi_{\mathrm{tMin}}^{*}\right], \text { se } \pi_{\mathrm{tMin}}^{*}<E(\pi)<\text { se } \pi_{\mathrm{tMax}}^{*} \\
0 \text { se } \mathrm{E}(\pi) \geq \pi_{\mathrm{tMax}}^{*} \text { ou } \mathrm{E}(\pi) \leq \pi_{\mathrm{tMin}}^{*}
\end{array}\right.
$$


De Mendonça e Machado (2013) desenvolvem um índice que mensura a credibilidade da política fiscal. O índice assume valor iguala 1 quando a expectativa do mercado sobre a dívida pública para os 12 meses seguintes é menor ou igual que o limite inferior (quando a razão dívida pública/PIB é de $40 \%$ ), pois nesse caso o risco de desequilíbrio físcal é nulo. O índice assume valor igual a 0 quando a expectativa do mercado sobre a dívida pública para os 12 meses seguintes é maior ou igual que o limite superior (quando a razão dívida pública/PIB é de $60 \%$ ), porque nesse caso há elevada probabilidade de ocorrência de um desequilíbrio fiscal.

O limite inferior e o limite superior foram estabelecidos no Tratado de Maastricht e, dessa forma, é uma referência para os países. Quando a expectativa do mercado se situa entre o limite inferior e superior, o índice assume valores entre 0 e 1 e, nesse caso, o risco de desequilíbrio fiscal cresce de forma linear à medida que se aproxima do limite superior, como pode ser observado na Equação 2 apresentada a seguir:

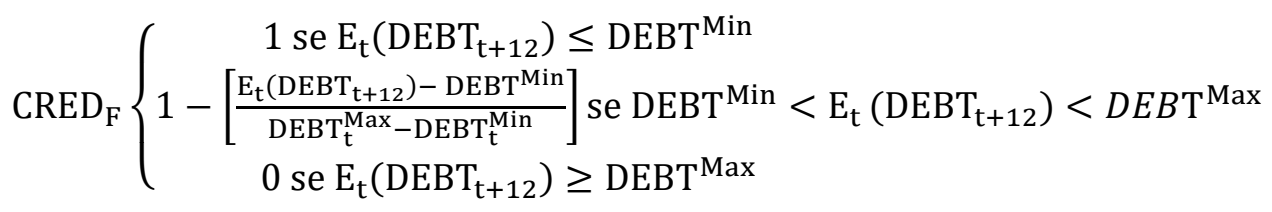

Por meio da metodologia dos mínimos quadrados ordinários (MQO) e do método generalizado dos momentos (GMM), os autores concluíram que para o período em análise (dezembro de 2003 até julho de 2011) o compromisso do governo com a dívida pública aumentou a credibilidade fiscal. Eles ressaltam que a credibilidade fiscal é de fundamental importância para o sucesso da gestão da dívida pública e, consequentemente, para a diminuição do risco de default. Segundo os autores, para que o governo possua uma gestão eficiente da dívida pública ele precisa estabilizar a inflação e a taxa de câmbio e implementar uma política fiscal crível.

Montes e Machado (2014) analisaram para o Brasil durante o período de 2003 a 2013 a influência da credibilidade da política monetária e da política fiscal sobre a taxa básica de juros (taxa Selic). Os métodos econométricos utilizados foram MQO, GMM e sistemas de equações de GMM. Os resultados empíricos mostraram que a credibilidade de ambas as políticas possui uma relação negativa com a taxa básica de juros para o período em análise. Assim sendo, quanto maior a credibilidade da política econômica menor tende a ser a taxa Selic. A análise empírica também apontou para uma relação negativa entre uma pior administração da estrutura de indexação da dívida pública brasileira com o comportamento da taxa de juros. 
Os autores também analisaram a influência do mecanismo de transmissão da política monetária pelo canal do preço dos ativos sobre o investimento agregado. A análise do mecanismo de transmissão da política monetária é baseada na teoria do $q$ de Tobin. Essa teoria fornece um mecanismo de explicação sobre a influência do mercado acionário na economia.

A teoria proposta por Tobin (1969) sugere que as empresas nas suas decisões de investimento levam em consideração a razão entre o valor de mercado do capital instalado e o seu custo de reposição. Os resultados encontrados mostram que a política monetária, por meio da taxa de juros Selic, afeta o $q$ de Tobin. Nestes termos, influência o investimento agregado.

De acordo com de Silva e Divino (2013), o qual visava analisar a relação entre política monetária e o prêmio de risco de mercado para o Brasil, o prêmio de risco possui relevância para explicar os ciclos econômicos no país. O prêmio de risco é um canal de transmissão da política monetária via canal de crédito.

Dessa forma, a literatura aponta para a importância da credibilidade da política monetária e da política fiscal para promover um ambiente econômico estável e para as tomadas de decisões de investimento dos agentes econômicos.

\section{Metodologia}

Na presente seção apresenta-se uma breve descrição das variáveis quantitativas, e o procedimento econométrico para mensurar o efeito da credibilidade da política monetária e da política fiscal na bolsa de valores brasileira.

\subsection{Descrição das variáveis}

Os dados são séries temporais e possuem periodicidade mensal utilizados com o objetivo estimar três modelos econométricos para medir o efeito da credibilidade sobre três índices de ações em bolsa. Destaca-se que os critérios de escolha dessas variáveis baseiam-se na revisão bibliográfica realizada na seção 2 e no princípio da parcimônia. Dessa forma, busca-se assegurar que os modelos possuam poder explicativo.

\subsubsection{Modelo do índice do setor industrial (INDX)}


O modelo do INDX será estimado de acordo com a equação a seguir:

$$
\operatorname{INDX}_{\mathrm{t}}=\mathrm{X}_{\mathrm{t}} \hat{\beta}+\widehat{\mu_{\mathrm{t}}}
$$

Onde $\operatorname{INDX}_{\mathrm{t}}$ é o vetor coluna da variável dependente que mede o índice do setor industrial, $\widehat{\beta}$ é o vetor coluna dos parâmetros, $X_{t}$ é a matriz das variáveis independente se $\widehat{\mu_{t}}$ é o vetor coluna dos resíduos do modelo, ou seja, tudo o que não é explicado pelas variáveis independentes/explicativas. O período em análise compreende os anos de 2005 a 2016.

O INDX mede o desempenho das ações mais representativas do setor industrial. Sua carteira teórica possui 45 ações e dentre estas 18 fazem parte do Ibovespa. Para a estimação desse modelo são utilizadas as seguintes variáveis explicativas: o Ibovespa, a credibilidade da política monetária e a credibilidade da política fiscal.

O índice da Bolsa de Valores Brasileira, o Ibovespa, representa o comportamento médio do mercado de ações brasileiro e sua carteira teórica possui 59 ações dos diferentes setores da economia. A variável índice de credibilidade da política monetária é calculada com base na mediana do índice de expectativas mensal acumulada para os próximos 12 meses do IPCA, dos analistas de mercado. A hipótese testada é a de que um aumento na credibilidade monetária irá aumentar o INDX.

A variável credibilidade da política fiscal é mensurada por meio da série divulgada pelo Banco Central das expectativas mensais para o ano seguinte do resultado nominal, como proporção do PIB. Dessa forma, a hipótese testada é de uma relação positiva entre o índice de credibilidade fiscal e o INDX.

\subsubsection{Modelo do índice de consumo (ICON)}

O modelo do ICON será estimado de acordo com a equação a seguir:

$$
\operatorname{ICON}_{\mathrm{t}}=\mathrm{X}_{\mathrm{t}} \widehat{\beta}+\widehat{\mu_{\mathrm{t}}}
$$

Onde $\mathrm{ICON}_{\mathrm{t}}$ é o vetor coluna da variável dependente que mede o índice do setor de consumo, $\widehat{\beta}$ é o vetor coluna dos parâmetros, $X_{t}$ é a matriz das variáveis independente se $\widehat{\mu_{t}}$ é o vetor coluna dos resíduos do modelo, ou seja, tudo o que não é explicado pelas variáveis independentes/explicativas. O período em análise compreende os anos de 2007 a 2016.

O ICON mede o desempenho médio das ações de maior representatividade dos setores de consumo cíclico, consumo não cíclico e saúde. Este índice é composto por 49 ações dente as quais 17 fazem parte do Ibovespa. 
Para a estimação desse modelo serão utilizadas as seguintes variáveis explicativas: o Ibovespa, a credibilidade da política monetária e credibilidade da política fiscal. As três variáveis são as mesmas que são utilizadas no modelo do INDX, as quais foram descritas na seção anterior.

\subsubsection{Modelo do índice financeiro (IFNC)}

O modelo do IFNC será estimado de acordo com a equação a seguir:

$$
\mathrm{IFNC}_{\mathrm{t}}=\mathrm{X}_{\mathrm{t}} \widehat{\beta}+\widehat{\mu_{\mathrm{t}}}
$$

$\mathrm{O} \mathrm{IFNC}_{\mathrm{t}}$ é o vetor coluna da variável dependente que mede o índice do setor

financeiro, $\widehat{\beta}$ é o vetor coluna dos parâmetros, $X_{t}$ é a matriz das variáveis independentes se $\widehat{\mu_{t}}$ é o vetor coluna dos resíduos do modelo, ou seja, tudo o que não é explicado pelas variáveis independentes/explicativas. O período em análise compreende os anos de 2005 a 2016.

O IFNC mede o desempenho médio das ações de maior representatividade dos setores de intermediários financeiros, serviços financeiros diversos, previdência e seguro. O índice possui 15 ações dentre as quais 9 deles fazem parte do Ibovespa.

Para a estimação desse modelo são utilizadas as seguintes variáveis explicativas: o Ibovespa, a credibilidade da política monetária e credibilidade da política fiscal. As três variáveis são as mesmas que serão utilizadas no modelo do INDX e do ICON, as quais foram descritas na seção do modelo do IDNX.

\subsection{Método}

Como os dados são séries temporais, a metodologia consiste em testar, diagnosticar e, caso necessário, corrigir os problemas associados a séries de tempo. Por isso, buscam-se estimadores que sejam não viesados e que no momento de realizar inferências estatísticas, sejam eficientes. Dessa forma, evitando a ocorrência de resultados espúrios.

Mesmo que as séries temporais não sejam estacionárias, elas podem apresentar uma dinâmica em comum, isto é, possuírem um comportamento estável de longo prazo. Dessa forma, duas séries são ditas cointegradas se compartilharem uma combinação linear estacionária, ou seja, se a relação linear entre elas for de equilíbrio. Formalmente, existe 
cointegração entre as séries quando o vetor de cointegração define uma combinação linear entre os elementos do regressor, no sentido de seguir uma tendência em comum sem desvios. Entretanto, no curto prazo há desvios dessa tendência em comum (BUENO, 2011).

Quando existe uma relação de longo prazo, os testes de cointegração vão indicar qual é essa relação. Entretanto, no curto prazo pode haver desequilíbrios, ou seja, eventuais distúrbios. Esses desequilíbrios muitas vezes são passageiros, podendo ser corrigidos através do termo de erro (GUJARATI; PORTER, 2011) e a regressão que analisa esse comportamento de curto prazo é o mecanismo de correção de erros.

Os modelos econômicos em geral são expressos por meio de diversas variáveis (modelos multivariados). Dessa forma, os modelos univariados são limitados para expressar modelos econômicos. A metodologia de vetores autorregressivos (VAR) permite que se expressem de forma completa os modelos econômicos (BUENO, 2011).

\section{Análise dos resultados}

Nesta seção são apresentados os principais resultados econométricos encontrados para cada um dos modelos em estudo. Primeiro, na seção 4.1 apresentam-se os modelos de variáveis dependentes para os índices em nível. Na seção 4.2 analisam-se os resultados dos modelos de cointegração para os retornos do IBOVESPA e índices setoriais da bolsa, em relação aos índices de credibilidade.

\subsection{Modelo dos índices setoriais}

Com o objetivo de evitar a obtenção de resultados espúrios na estimação dos modelos de curto prazo foram feitos os testes Dickey-Fuller Ampliado (ADF) para detectar a presença de raiz unitária nas séries em estudo. De acordo com os testes realizados, verificou-se que todas as variáveis são não estacionárias em nível. Porém, ao se considerar as variáveis em primeira diferença verificou-se que elas são estacionárias, com exceção da variável credibilidade da política fiscal, a qual é estacionária apenas em segunda diferença. Dessa forma, pode-se dizer que as séries INDX, IBOV e Credibilidade da Política Monetária são integradas de primeira ordem I(1), enquanto a variável Credibilidade da Política Fiscal é integrada de segunda ordem $\sim \mathrm{I}(2)$. 
Revista Catarinense de Economia -RCE

APEC - Associação dos Pesquisadores em Economia Catarinense

10 Semestre de 2018 - www.apec.pro.br/rce

Para mensurar o modelo do INDX foi utilizado o mecanismo de correção de erros (MCE), porque este mecanismo fornece a rapidez com que os desequilíbrios de curto prazo são corrigidos e, consequentemente, levam ao equilíbrio. A regressão consiste no uso da primeira diferença das variáveis que são I(1) e no uso da segunda diferença das variáveis que são I(2), acrescentando como variável independente o erro defasado do modelo com as todas as variáveis em nível, com exceção da variável credibilidade da política fiscal a qual foi usada em primeira diferença, porque para que as variáveis cointegrem é necessário que elas sejam de mesma ordem para se tornarem estacionárias. Se o erro defasado for estatisticamente significativo isso mostra que as variações do presente estão sendo influenciadas pelo passado.

Contudo, para que as variáveis cointegrem não é condição suficiente que elas tenham a mesma ordem, porque os resíduos do modelo também precisam ser estacionários. Ao analisar os resultados do modelo das variáveis em INDX, IBOV e Credibilidade da Política Monetária em nível e na primeira diferença da Credibilidade da Política Fiscal se verificou que os resíduos não são estacionários. Portanto, as variáveis não cointegram e o MCE não pôde ser usado para analisar a relação entre essas variáveis.

Para mensurar o modelo curto prazo do ICON também foi utilizado o mecanismo de correção de erros (MCE), porque este mecanismo fornece a rapidez com que os desequilíbrios de curto prazo são corrigidos. Dessa forma, os mesmos procedimentos econométricos utilizados no mecanismo de correção de erros do modelo do INDX foram usados para estimar o modelo do ICON.

A variável ICON, por meio do teste de Dickey-Fuller Ampliado (ADF), mostrou-se não estacionária em nível. Porém, ao se considerar a variável em primeira diferença ela se mostrou estacionária. Dessa forma, ao se regredir as variáveis ICON, IBOV e Credibilidade da Política Monetária em nível e na primeira diferença da Credibilidade da Política Fiscal se verificou que os resíduos não são estacionários. Portanto, as variáveis não cointegram e o MCE não pôde ser usado para analisar a relação entre essas variáveis.

Para mensurar o modelo de curto prazo do IFNC também foi utilizado o mecanismo de correção de erros (MCE). Dessa forma, os mesmos procedimentos econométricos utilizados no mecanismo de correção de erros do modelo do INDX e do ICON foram usados para estimar o modelo do IFNC.

A variável IFNC, por meio do teste de Dickey-Fuller Ampliado (ADF), mostrou-se não estacionária em nível. Porém, ao se considerar a variável em primeira diferença ela se mostrou estacionária. Dessa forma, ao se regredir as variáveis IFNC, IBOV e Credibilidade da 
Política Monetária em nível e na primeira diferença da Credibilidade da Política Fiscal, verificou-se que os resíduos são estacionários. Portanto, as variáveis cointegrem e o MCE pôde ser usado para analisar a relação entre essas variáveis. A Tabela 1 mostra os principais resultados obtidos do MCE.

Tabela 1- Principais Resultados do MCE do Modelo do IFNC

\begin{tabular}{cccc}
\hline Variável & Coeficiente & p-valor & \\
\hline Constante & 0,00666813 & 0,063 & $*$ \\
d log(Ibovespa) & 1,00013 & 0,0001 & $* * *$ \\
$\mathrm{~d}($ Credibilidade PM) & $-0,00358264$ & 0,7778 & \\
$\mathrm{~d}($ Credibilidade PF $)$ & $-0,0200732$ & 0,0958 & \\
Erro(-1) & $-0,0527395$ & & $* * *$ \\
\hline $\mathrm{R}^{2}$ - ajustado & & 0,855594 & \\
Durbin-Watson & & 1,921118 & \\
\hline
\end{tabular}

Fonte: Resultados obtidos na pesquisa.

O coeficiente do erro defasado é estatisticamente significativo com nível de significância de $1 \%$, portanto o MCE existe. Além disso, o coeficiente está entre 0 e -1, indicando que os desequilíbrios de curto prazo são corrigidos e o modelo converge para o equilíbrio de longo prazo. Os resultados mostram que são necessários cerca de 18 meses para que os desequilíbrios de curto prazo do IFNC sejam corrigidos e retornem ao nível de equilíbrio de longo prazo.

Os resultados da regressão indicam que no curto prazo a variável Ibovespa é estatisticamente significativa com nível de significância de $1 \%$ para explicar as variações no IFNC. Ou seja, quando o Ibovespa aumenta em $1 \%$ o IFNC tende a aumentar em cerca de $1 \%$ também.

As variáveis Credibilidade da Política Fiscal e Credibilidade da Política Monetária não foram estatisticamente significativas no modelo. Dessa forma, indicando que para o período de análise elas não influenciaram o comportamento do IFNC.

\subsection{Modelo de retorno dos índices setoriais}

Nesta seção as tabelas 2 e 3 mostram os resultados das regressões entre os retornos e os índices de credibilidade, apontando significância estatística dos efeitos da credibilidade de política monetária sobre as taxas de retorno dos índices. Cabe destacar que pelos testes de 
cointegração a hipótese de não estacionariedade para os retornos falha, apesar dos resíduos serem estacionários. Tudo leva a crer que as regressões são espúrias.

Tabela 2- Regressões de Retornos de IBOVESPA, INDX e o MCE

Retorno IBOVESPA (Jan/2002-dez/2016) Retorno INDX (Jan/2002-dez/2016) MQO com Erro Padrão Robusto MQO com Erro Padrão Robusto

\begin{tabular}{|c|c|c|c|c|c|c|}
\hline & \multicolumn{3}{|c|}{ MQO com Erro Padrão Robusto } & \multicolumn{3}{|c|}{ MQO com Erro Padrão Robusto } \\
\hline & Parâmetros & Erro-padrão & p-valor & Parâmetros & Erro-padrão & p-valor \\
\hline Constante & NE & NE & NE & NE & NE & NE \\
\hline $\mathrm{ICPF}$ & $-0,0290908$ & $\mathbf{0 , 0 1 3 4 6}$ & 0,03200 & $-0,0252391$ & 0,01075 & 0,02000 \\
\hline ICPM & $\mathbf{0 , 0 8 5 7 7 8 2}$ & 0,019302 & 0,00000 & 0,0875322 & $\mathbf{0 , 0 1 5 1 1 5 5}$ & 0,00000 \\
\hline $\mathrm{R}^{2}$-ajustado & \multicolumn{3}{|c|}{0,0437} & \multicolumn{3}{|c|}{0,062499} \\
\hline Durbin-Watson & \multicolumn{3}{|c|}{1,961234} & \multicolumn{3}{|c|}{1,835914} \\
\hline & \multicolumn{3}{|c|}{ Diferença do Retorno IBOVESPA } & \multicolumn{3}{|c|}{ Diferença do Retorno INDX } \\
\hline & \multicolumn{3}{|c|}{ MQO com MCE (Erro Padrão Robusto) } & \multicolumn{3}{|c|}{ MQO com MCE (Erro Padrão Robusto) } \\
\hline DICPF & 0,19068 & 0,22763 & 0,40340 & 0,09125 & 0,17913 & 0,61110 \\
\hline DICPM & 0,07029 & 0,06354 & 0,27020 & 0,06188 & 0,05848 & 0,29150 \\
\hline Resíduo (t - 1) & $-0,992661$ & 0,134917 & 0,00000 & $-0,920414$ & 0,170479 & 0,00000 \\
\hline $\mathrm{R}^{2}$-ajustado & \multicolumn{3}{|c|}{0,489145} & \multicolumn{3}{|c|}{0,450636} \\
\hline Durbin-Watson & \multicolumn{3}{|c|}{1,999979} & \multicolumn{3}{|c|}{2,031309} \\
\hline
\end{tabular}

Tabela 3- Regressões de Retornos de IEE, IFINC e ICON e o MCE

\begin{tabular}{|c|c|c|c|c|c|c|c|c|c|}
\hline & \multicolumn{3}{|c|}{$\begin{array}{c}\text { Retorno IEE (Jan/2002- } \\
\text { dez/2016) }\end{array}$} & \multicolumn{3}{|c|}{$\begin{array}{c}\text { Retorno IFINC (Jan/2005- } \\
\text { dez/2016) }\end{array}$} & \multicolumn{3}{|c|}{$\begin{array}{c}\text { Retorno ICON (Jan/2007- } \\
\text { dez/2016) }\end{array}$} \\
\hline & \multicolumn{3}{|c|}{$\begin{array}{l}\text { MQO com Erro Padrão } \\
\text { Robusto }\end{array}$} & \multicolumn{3}{|c|}{$\begin{array}{l}\text { MQO com Erro Padrão } \\
\text { Robusto }\end{array}$} & \multicolumn{3}{|c|}{$\begin{array}{l}\text { MQO com Erro Padrão } \\
\text { Robusto }\end{array}$} \\
\hline & Parâmetros & $\begin{array}{c}\text { Erro- } \\
\text { padrão }\end{array}$ & $\begin{array}{c}\mathrm{p}- \\
\text { valor }\end{array}$ & Parâmetros & $\begin{array}{c}\text { Erro- } \\
\text { padrão }\end{array}$ & $\begin{array}{c}\mathrm{p}- \\
\text { valor }\end{array}$ & Parâmetros & $\begin{array}{c}\text { Erro- } \\
\text { padrão }\end{array}$ & $\begin{array}{c}\mathrm{p}- \\
\text { valor }\end{array}$ \\
\hline Constante & NE & $\mathrm{NE}$ & NE & NE & $\mathrm{NE}$ & $\mathrm{NE}$ & $-0,142530$ & 0,07096 & 0,04690 \\
\hline ICPF & $-0,0222937$ & 0,01241 & 0,07420 & $-0,0148726$ & 0,01469 & 0,31310 & 0,11750 & 0,06259 & 0,06300 \\
\hline ICPM & 0,0812797 & 0,0202492 & 0,00009 & 0,0707192 & 0,0340254 & 0,03950 & 0,12867 & 0,052017 & 0,01480 \\
\hline $\mathrm{R}^{2}$-ajustado & \multicolumn{3}{|c|}{0,045322} & \multicolumn{3}{|c|}{0,024122} & \multicolumn{3}{|c|}{0,031378} \\
\hline Durbin-Watson & \multicolumn{3}{|c|}{1,963095} & \multicolumn{3}{|c|}{1,923108} & \multicolumn{3}{|c|}{1,793433} \\
\hline & \multicolumn{3}{|c|}{ Diferença do Retorno IEE } & \multicolumn{3}{|c|}{ Diferença do Retorno IFINC } & \multicolumn{3}{|c|}{ Diferença do Retorno ICON } \\
\hline & \multicolumn{3}{|c|}{$\begin{array}{c}\text { MQO com MCE (Erro } \\
\text { Padrão Robusto) }\end{array}$} & \multicolumn{3}{|c|}{$\begin{array}{c}\text { MQO com MCE (Erro } \\
\text { Padrão Robusto) }\end{array}$} & \multicolumn{3}{|c|}{$\begin{array}{c}\text { MQO com MCE (Erro } \\
\text { Padrão Robusto) } \\
\end{array}$} \\
\hline DICPF & 0,13258 & 0,25416 & 0,60260 & 0,41147 & 0,26991 & 0,12960 & 0,14679 & 0,23900 & 0,54030 \\
\hline DICPM & 0,05197 & 0,07768 & 0,50440 & 0,09867 & 0,10046 & 0,32770 & 0,09542 & 0,08691 & 0,27450 \\
\hline Resíduo (t - 1) & $-0,988764$ & 0,112628 & 0,00000 & $-0,952137$ & $\mathbf{0 , 0 9 6 8 9 3 2}$ & 0,00000 & $-0,890503$ & 0,157438 & 0,00000 \\
\hline $\mathrm{R}^{2}$-ajustado & \multicolumn{3}{|c|}{0,486247} & \multicolumn{3}{|c|}{0,477775} & \multicolumn{3}{|c|}{0,43338} \\
\hline Durbin-Watson & \multicolumn{3}{|c|}{2,011333} & \multicolumn{3}{|c|}{1,995334} & \multicolumn{3}{|c|}{2,024641} \\
\hline
\end{tabular}


Vale apena interpretar tais resultados, já que o coeficiente de credibilidade de política monetária permaneceu significativo para todas as regressões. Neste contexto, abstraindo a ausência de cointegração, podemos inferir que em média um aumento de 0,1 ponto no indicador de credibilidade monetária implica em aumento entre 0,7 e 1,2 pontos percentuais na taxa de retorno dos índices.

Nas regressões de curto prazo os coeficientes não apresentaram significância estatística, mas o mecanismo de correção de erros respeitou a restrição e apresentou significância, mostrando que o ajuste é quase imediato para a equação de longo prazo.

\section{Considerações finais}

O trabalho realizado buscou analisar para o Brasil em que proporção a credibilidade da política monetária e a credibilidade da política fiscal afetaram os índices setoriais INDX, ICON e IFNC, devido a importância que essas variáveis possuem na determinação de como e onde os recursos da economia serão alocados.

Por meio da revisão bibliográfica notou-se que a literatura aponta que a credibilidade da política monetária é importante para manter a inflação na meta e estável e, consequentemente, gerar um ambiente econômico estável para a tomada de decisões dos agentes econômicos. Além disso, a literatura também ressalta a relevância do comprometimento do governo com a responsabilidade fiscal para dar transparência e sustentabilidade para as finanças públicas e, consequentemente, também ser responsável por gerar um ambiente econômico estável.

Partindo para o contexto econométrico do estudo, o modelo de curto prazo do IFNC mostrou que para o período de 2007 a 2016, o Ibovespa foi a variável responsável por explicar as variações no IFNC, porque ela foi estatisticamente significativa. Por outro lado, as variáveis Credibilidade da Política Monetária e Credibilidade da Política Fiscal não foram estatisticamente significativas, indicando que não existe uma associação linear com o IFNC. Portanto, as variações na Bolsa de Valores brasileira são as principais responsáveis pelas flutuações no IFNC para o período em análise.

Nas regressões entre os retornos e os índices de confiança, observou-se significância estatística dos efeitos da credibilidade de política monetária sobre as taxas de retorno dos índices. Nas regressões de curto prazo os coeficientes não apresentaram significância 
Revista Catarinense de Economia -RCE

APEC - Associação dos Pesquisadores em Economia Catarinense

1은 Semestre de 2018 - www.apec.pro.br/rce

estatística e o mecanismo de correção de erros mostrou que o ajuste é quase imediato em direção a tendência de longo prazo.

Por fim, salienta-se que o estudo está restrito a forma como a credibilidade da política monetária e a credibilidade da política fiscal são mensuradas. Logo, é interessante que outros estudos utilizem abordagens diferentes para mensurar a credibilidade da política monetária e a credibilidade da política fiscal.

\section{Referências}

BARRO, Robert J.; GORDON, David B. Rules, Discretion and Reputation in a model of monetary policy. Journal of Monetary Economics, North-Holland, v. 12, p. 101-121, jan./mar. 1983.

BLANCHARD, Oliver; JOHNSON, David R. Macroeconomia. 6a Edição. New Jersey: Pearson Education, 2013.

BRASIL. Diário Oficial da República Federativa do Brasil, Lei $\mathbf{n}^{\circ}$ 101, de 4 de maio de 2000. Estabelece normas de finanças públicas voltadas para a responsabilidade na gestão fiscal e dá outras providências. Brasília, DF, 5 de maio de 2000. Disponível em: <https://www.planalto.gov.br/ccivil_03/leis/lcp/lcp101.htm〉. Acesso em:10 mar. 2017.

BUENO, Rodrigo De Losso Da Silveira. Econometria de séries temporais. 2 ed.São Paulo: Cengage Learning, 2011.

DORNBUSCH, Rudiger; FISCHER, Stanley; STARTZ, Richard. Macroeconomia. 11ªdição. São Paulo: McGraw-Hill, 2013.

GUJARATI, Damodar N.; PORTER, Dawn C. Econometria básica. 5 ed. Porto Alegre: AMGH, 2011.

KYDLAND, Finn E.; PRESCOTT, Edward C. Rules rather than discretion: the inconsistency of optimal plans. The Journal of Political Economy, Chicago, v. 85, n. 3, p. 473-492, jun./jul. 1977.

MANKIW, N. G. Macroeconomia. $7^{\text {a }}$ Edição. LTC. 2011.

MENDONÇA, HELDER FERREIRA DE. Mensurando a Credibilidade do Regime de Metas Inflacionárias no Brasil. Revista de Economia Política, São Paulo, v. 24, n. 3, p. 22-29, jul./set. 2004.

MENDONÇA, Helder Ferreira De; MACHADO, Marcelo Rangel. Public debt management and credibility: Evidence from an emerging economy. Economic Modelling, Amsterdã, v. 30, n. 1, p. 10-21, jan./fev. 2013.

MISHKIN, Frederic S. Monetary policy strategy.1 ed. Massachusetts: The MIT Press, 2007.

MONTES, Gabriel Caldas; MACHADO, Caroline Cabral. Expectativas empresariais, investimento agregado e emprego: uma análise considerando os efeitos das credibilidades monetária e fiscal no brasil. Economia Aplicada, São Paulo, v. 18, n. 3, p. 515-542, jul./set. 2014.

NORDHAUS, William. The political business cycle. The review of economic studies, 
Bristal, v. 42, n. 2, p. 169-190, abr./jun. 1975.

SALTO, Felipe; ALMEIDA, Mansueto. Finanças públicas: Da contabilidade criativa ao resgate da credibilidade. 1 ed. Rio de Janeiro: Record, 2016. 308 p.

SILVA, Rogério Lúcio Silva; DIVINO, José Angelo. Prêmio de risco e a política monetária no brasil. Economia Aplicada, São Paulo, v. 17, n. 2, p. 163-192, jan./fev. 2013.

TOBIN, James. A general equilibrium approach to monetary theory. Journal of money, credit and banking, Columbus, v. 1, n. 1, p. 15-29, jan./fev. 1969.

WOOLDRIDGE, Jeffrey M. Introdução à econometria: Uma abordagem moderna.4 ed. São Paulo: Cengage Learning, 2011. 